\section{J wave syndromes as a cause of sudden arrhythmic death}

\author{
Charles Antzelevitch \\ Masonic Medical Research Laboratory, \\ Utica, NY, USA
}

\section{Abstract}

Accentuated $\mathrm{J}$ waves have been associated with idiopathic ventricular tachycardia and fibrillation (VT/VF) for nearly three decades. Prominent $\mathrm{J}$ waves characterize both Brugada and early repolarization syndromes leading to their designation as $\mathrm{J}$ wave syndromes. An early repolarization (ER) pattern, characterized by $\mathrm{J}$ point elevation, slurring of the terminal part of the QRS and ST segment elevation was considered to be a totally benign electrocardiographic manifestation until a decade ago. Recent casecontrol and population-based association studies have advanced evidence that an ER pattern in the inferior or infero-lateral leads is associated with increased risk for life-threatening arrhythmias, named early repolarization syndrome (ERS). ERS and Brugada syndrome (BrS) share similar electrocardiogram features, clinical outcomes, risk factors as well as a common arrhythmic platform related to amplification of $\mathrm{I}_{\mathrm{to}}$-mediated $\mathrm{J}$ waves. Although $\mathrm{BrS}$ and ERS differ with respect to the magnitude and lead location of abnormal J wave manifestation, they are thought to represent a continuous spectrum of phenotypic expression, termed $\mathrm{J}$ wave syndromes. A classification scheme for ERS has been proposed: type 1, displaying an ER pattern predominantly in the lateral precordial leads, is considered to be largely benign; type 2 , displaying an ER pattern predominantly in inferior or infero-lateral leads, is associated with a higher level of risk; whereas type 3 , displaying an ER pattern globally in inferior, lateral and right precordial leads, is associated with the highest level of risk for development of malignant arrhythmias and is often associated with VF storms.

\section{Evolution of the $\mathrm{J}$ wave syndromes}

Early repolarization syndrome (ERS) and Brugada syndrome (BrS) share similar electrocardiogram (ECG) features, clinical outcomes, risk factors as well as a common arrhythmic platform related to amplification of $\mathrm{I}_{\mathrm{t} 0}$-mediated J waves. ${ }^{1}$

Also referred to as the 0sborn wave, the $\mathrm{J}$ wave or elevated $\mathrm{J}$ point has been described in the ECG of animals and humans for over six decades, ${ }^{2}$ since Osborn's observation in the early $1950 \mathrm{~s} .{ }^{3}$ In humans, the appearance of a prominent $\mathrm{J}$ wave in the ECG is considered pathognomonic of hypothermia, ${ }^{4-6}$ hypercalcemia $^{7,8}$ and more recently as a marker for a substrate capable of generating life-threatening ventricular arrhythmias. ${ }^{9} \mathrm{~A}$ distinct $\mathrm{J}$ wave has been described in subjects completely recovered from hypothermia ${ }^{10,11}$ or those predisposed to idiopathic ventricular fibrillation (IVF), but is otherwise rarely observed in humans under normal conditions. In animals, a distinct $\mathbf{J}$ wave is commonly observed in the ECG of some species, including Baboons and dogs, under baseline conditions and is greatly amplified under hypothermic conditions. ${ }^{12-14}$ An elevated J point is commonly encountered in humans and some animal species under normal conditions.

An early repolarization (ER) pattern in the ECG has in recent years been shown to be associated with life-threatening arrhythmias, earning the designation of ERS. Although BrS and ERS differ with respect to lead location and magnitude of abnormal $J$ wave manifestation, they have been proposed to represent a continuous spectrum of phenotypic expression termed J wave syndromes. ${ }^{9}$

An ER pattern, consisting of $\mathbf{J}$ point elevation or a distinct $J$ wave, a notch or slur of the terminal part of the QRS and an ST segment elevation, is commonly found in healthy young males and has long been considered to be benign. ${ }^{15,16}$ Our observation in 2000 that an early repolarization pattern in the canine coronary-perfused wedge preparation can convert to one in which phase 2 reentry gives rise to polymorphic ventricular tachycardia and fibrillation (VT/VF), prompted the suggestion that ER may in some cases predispose to malignant arrhythmias in the clinic. ${ }^{9,17,18}$ A growing number of case control and population-based studies as well asexperimental studies have suggested a critical role for the $\mathrm{J}$ wave in the pathogenesis of IVF. ${ }^{19-27} \mathrm{~A}$ conclusive association between ER and IVF was presented in the form of two studies published in the New England Journal of Medicine in 2008..$^{28,29}$ These were followed by another study from Viskin and co-workers ${ }^{30}$ that same year and large population-based association studies in 2009 and $2010 . .^{31-35}$

In a case-control study of 206 patients who survived an episode of IVF and 412 matched control subjects, Haissaguerre and co-workers demonstrated that $31 \%$ of the IVF group, compared to $5 \%$ of the controls displayed an early repolarization pattern consisting of a $\mathrm{J}$ point elevation $(>0.1 \mathrm{mV})$, slurring of the terminal part of the QRS and ST segment elevation in the inferior and/or lateral ECG leads. ${ }^{31}$

In the same issue of the New England Journal of Medicine, Nam and co-workers
Correspondence: Charles Antzelevitch, Masonic Medical Research Laboratory, 2150 Bleecker Street, Utica, NY 13501, USA.

Tel. +315.735.2217 - Fax: +315.735 .5648 .

E-mail: ca@mmrl.edu

Key words: cardiac arrhythmias, sudden cardiac death, early repolarization syndrome, brugada syndrome, idiopathic ventricular fibrillation.

Funding: Supported by grant HL47678 from NHLBI, NYSTEM grant C026424 and Masons of New York State, Florida, Massachusetts Maryland, Rhode Island Connecticut.

Conflict of interests: there are no conflict of interests to disclose.

Received for publication: 30 December 2011. Revision received: 16 May 2013.

Accepted for publication: 17 May 2013.

This work is licensed under a Creative Commons Attribution NonCommercial 3.0 License (CC BYNC 3.0).

(C) Copyright C. Antzelevitch, 2013

Licensee PAGEPress, Italy

Cardiogenetics 2013; 3:e2

doi:10.4081/cardiogenetics.2013.e2

reported that $60 \%$ of their IVF patients displayed an ER pattern. ${ }^{29}$ Four of their patients presented with electrical storm (four or more episodes of ventricular fibrillation in one day). Continuous electrocardiographic monitoring of the patients with electrical storm revealed a unique electrocardiographic signature consisting of an early repolarization pattern in the infero-lateral leads at baseline and dramatic transient accentuation of the $J$ waves in the infero-lateral leads and the development of a marked $\mathrm{J}$ wave in the right precordial leads, where it had not appeared before, just before the development of electrical storm, which was precipitated by relatively short-coupled premature ventricular beat. ${ }^{29}$ The accentuated J waves and VF could be suppressed with quinidine and isoproterenol or with pacing at increasingly rapid rates. Interestingly, unlike in patients $\mathrm{BrS}$, the electrocardiographic and arrhythmic abnormalities could not be provoked with intravenous flecainide in these type 3 ERS patients.

Several case-control studies followed confirming the association between ER and IVF.,36-40 A recent case-control study explored the prognostic significance of ER among chronic coronary disease patients with implantable cardioverterdefibrillator (ICD) ${ }^{41}$ The prevalence of inferior ER was significantly greater among patients who had appropriate ICD therapy for ventricular arrhythmias than in patients who were arrhythmia-free ( $28 \%$ vs $8 \%, \mathrm{P}=0.011)$, irrespective of 
their ejection fraction. Rgwy noted that ER prevalence was much greater among young males compared to females and that the higher prevalence in males declines rapidly with age, suggesting a potential influence of testosterone as a modifier of J-wave or ER manifestation. This male predominance is observed with all of the $\mathrm{J}$ wave syndromes, ${ }^{9}$ including Brugada syndrome. $^{42}$

The prevalence and prognosis of inferior or infero-lateral ER have also been studied in several general population studies. ${ }^{31,32,34,35,40}$ In a study of 10,864 middle-aged Fins enrolled in a population-based study of coronary heart disease between (1966-1972) with a mean followup of $30 \pm 11$ years, the prevalence of inferolateral ER at entry was 5.8\%. Inferior ER was associated with increased risk of cardiac mortality [relative risk (RR) $1.28, \mathrm{P}=0.03$ ], and inferior ER patterns with J-point elevations greater than $0.2 \mathrm{mV}$ was associated with cardiac mortality (RR 2.98, $\mathrm{P}<0.001)$ and sudden arrhythmic death (RR 2.92, $\mathrm{P}=0.01$ ). Interestingly, QTc durations $>440 \mathrm{~ms}$ in males and $460 \mathrm{~ms}$ in females were associated with a smaller magnitude of increased risk for cardiac mortality (RR 1.20, P=0.03).

This was followed by a population-based study reported by Sinner and co-workers examining the ER prevalence and prognosis in a German population of 1945 subjects from the KORA/MONICA cohort. ${ }^{32}$ Inferolateral ER was observed in $13.1 \%$ of the cohort, whereas inferior ER prevalence was 7.6\%, both higher than those observed in the Finnish study. The risk of death from cardiac causes was greater in relatively young males with inferior ER, ER pattern was associated with a 2- to 4-fold increased risk of cardiac mortality in individuals between 35 and 54 years.

In a subsequent publication from Tikkanen and co-workers based on the Finnish population, the authors subgrouped the inferior ER patterns into notched or slurred J-wave patterns and into ascending or horizontal/descending ST-segments following the J-wave. ${ }^{34}$ The risk for arrhythmic death did not differ between notched and slurred J-wave ER patterns, but they reported a higher risk for in subjects with horizontal or descending ST-segments in the inferior leads [RR 1.62, 95\% confifence interval (CI) 1.192.21] when compared to subjects with rapidly ascending ST segments [RR 1.01, $\mathrm{P}=$ not significant (NS)]. Rapidly ascending ST segments after the J-wave was the most prevalent pattern observed in athletes. A horizontal/ascending ST segment combined with a $2 \mathrm{~mm}$ J-point elevation was associated with a still higher risk for arrhythmic death (RR 3.37, 95\% CI 1.75-6.51). Rosso and co-workers reported similar results showing that a horizontal/descending ST segment following the J-point is associated with a higher level of risk for VT/NF. ${ }^{39}$

Another population-based study of atomic bomb survivors in the Nagasaki region of Japan $^{40}$ reported that in subjects followed over a period of 46 years, a stable ER pattern was found in 650 subjects resulting in a prevalence of $29.3 \%$. Mortality rates in subjects with ER did not show an increased risk for all-cause mortality or cardiac death, but the risk for sudden unexpected death was significantly higher among ER subjects, as in the other studies.

Based on a review of published clinical data, we recently suggested a classification scheme for ER. ${ }^{9}$ An ER pattern appearing exclusively in the lateral precordial leads was designated as type 1 ; this form is prevalent among healthy male athletes and is thought to be associated with a relatively low level of risk for arrhythmic events. ER pattern in the inferior or infero-lateral leads was designated as type 2; this form appears to be associated with a moderate level of risk. Finally, an ER pattern manifest globally in the inferior, lateral and right precordial leads was labeled type 3 ; this form is associated with the highest level of risk and has been associated with electrical storms. ${ }^{9}$ Of note, type 3 ER may often be similar to that of type 2 , exhibiting infero-lateral ER, except for brief periods just before the development of VT/NF when pronounced $\mathrm{J}$ waves are also observed in the right precordial leads (see Nam et al. ${ }^{43}$ for an exam- ple). BrS represents a fourth variant in which ER is limited to the right precordial leads.

\section{Mechanisms underlying the inscription of the electrocardiogram $J$ wave and associated arrhythmogenesis}

The cellular basis for the $\mathrm{J}$ wave was first identified in $1996 .{ }^{20}$ Transmural distribution of the transient outward current $\left(\mathrm{I}_{\mathrm{t} 0}\right)$-mediated action potential notch was shown to be responsible for the inscription of the electrocardiographic J wave. ${ }^{20,44,45}$ The ventricular epicardial action potential, particularly in the right ventricle, displays a prominent $\mathrm{I}_{\mathrm{to}}$-mediated notch or spike and dome morphology. The presence of a prominent $\mathrm{I}_{\mathrm{t} 0}$-mediated action potential notch in ventricular epicardium but not endocardium leads to the development of a transmural voltage gradient that manifests as a $\mathrm{J}$ wave or J point elevation on the ECG. ${ }^{46}$ Direct evidence in support of this hypothesis was first obtained in the arterially-perfused canine ventricular wedge preparation, ${ }^{20}$ as illustrated in Figure 1. Factors that modify the balance of

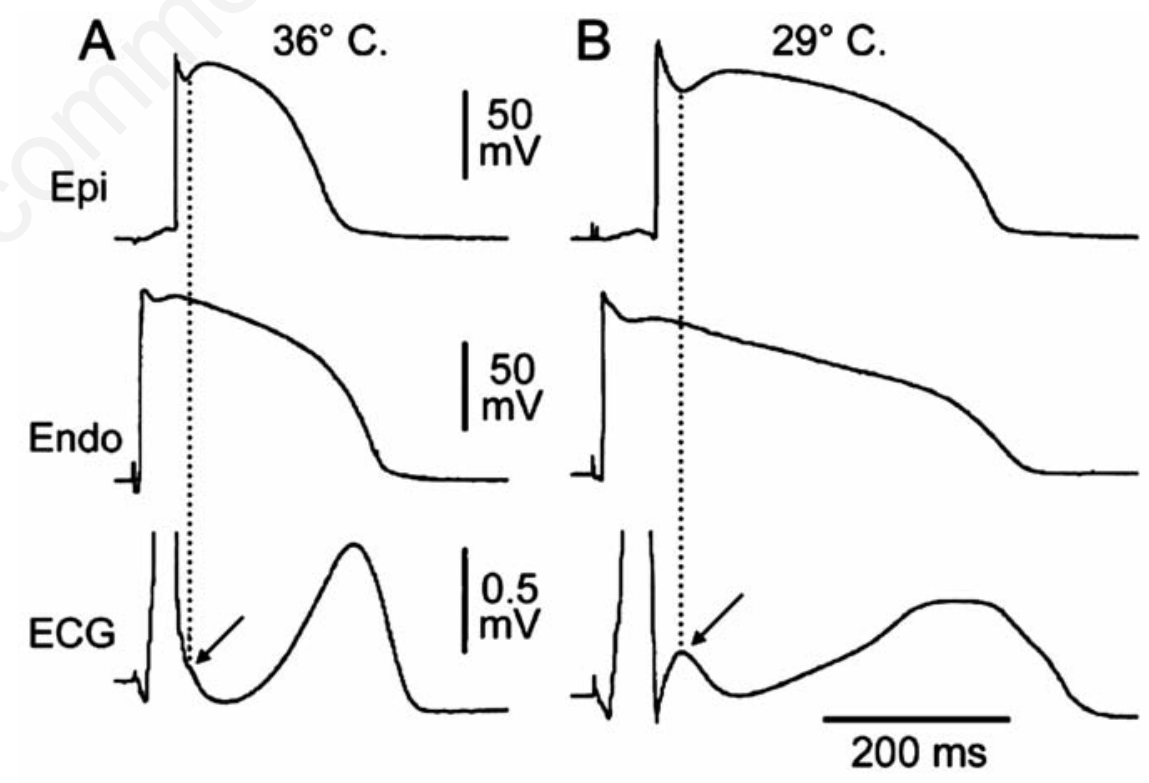

Figure 1. Hypothermia-induced J wave. Each panel shows transmembrane action potentials from the epicardial and endocardial regions of an arterially perfused canine left ventricular wedge and a transmural electrocardiogram (ECG) simultaneously recorded. A) The relatively small action potential notch in epicardium but not in endocardium is associated with an elevated J-point at the R-ST junction (arrow) at $36^{\circ} \mathrm{C}$. B) A decrease in the temperature of the perfusate to $29^{\circ} \mathrm{C}$ results in an increase in the amplitude and width of the action potential notch in epicardium but not endocardium, leading to the development of a transmural voltage gradient that manifests as a prominent $J$ wave on the ECG (arrow) (modified from Yan and Antzelevitch, 1996 ${ }^{\circ}$ with permission). 
currents contributing to the early phases of the action potential or ventricular activation sequence can modify the manifestation of the $\mathrm{J}$ wave on the ECG. Whether reduced by $\mathrm{I}_{\mathrm{to}}$ blockers such as quinidine, 4-aminopyridine, premature activation or augmented by exposure to hypothermia, $\mathrm{I}_{\mathrm{Ca}}$ and $\mathrm{I}_{\mathrm{Na}}$ blockers or $\mathrm{I}_{\mathrm{to}}$ agonists such as NS5806, changes in the magnitude of the epicardial action potential notch parallel those of the $\mathrm{J}$ wave. ${ }^{47-50}$

An outward shift in the balance of currents during phases 1 and 2 of the action potential, whether secondary to a decrease of inward currents or an increase of outward current, accentuates the action potential notch leading to augmentation of the $J$ wave or appearance of ST segment elevation. Further augmentation of net repolarizing current can result in partial or complete loss of the action potential dome, leading to a transmural voltage gradient that manifests as accentuation of the $\mathrm{J}$ wave or an ST segment elevation. ${ }^{18,47,48}$ In regions of the myocardium exhibiting a prominent $\mathrm{I}_{\mathrm{t} 0}$, such as the right ventricular epicardium, marked accentuation of the action potential notch gives rise to a prominent $\mathrm{J}$ wave, often characterized as a coved-type ST segment elevation, which is diagnostic of $\mathrm{BrS}$ (Figure 2B). Additional outward shift of the balance of current active during the early phase of the action potential leads to loss of the action potential dome, thus creating a dispersion of repolarization between epicardium and endocardium as well as within epicardium, between regions that lost the dome and regions at which the dome is maintained (Figure 2C). Sodium channel blockers like ajmaline, flecainide, procainamide, pilsicainide, propafenone and disopyramide cause a further outward shift of current flowing during the early phases of the action potential and therefore effective in inducing or unmasking ST segment elevation in patients with concealed J-wave syndromes. ${ }^{51-53}$ Some sodium channel blockers like quinidine, which also inhibits $\mathrm{I}_{\mathrm{t}}$, reduce the magnitude of the $J$ wave and normalize ST segment elevation. ${ }^{18,54}$ Loss of the action potential dome is usually heterogeneous, resulting in marked abbreviation of action potential at some sites but not others. The dome is then able to propagate from regions at which it is maintained to regions at which it is lost, giving rise to a very closely coupled extrasystole via phase 2 reentry (Figure 2D)..$^{55}$ The phase 2 reentrant beat is capable of initiating polymorphic VT or VF (Figure 2E and F).

While most investigators consider the pathophysiology of Brugada syndrome to be due to repolarization abnormalities, several studies have suggested the possibility that delayed depolarization in the right ventricular outflow tract underlies the development of ST segment elevation or $\mathrm{J}$ waves associated with BrS.56,57 The repolarization vs depolarization hypotheses controversy has been documented as a published debate. ${ }^{58}$

The net outward shift of current may extend beyond the action potential notch and thus lead to depression of the dome in addition to accentuating the $J$ wave. Activation of the ATP-sensitive potassium current $\left(\mathrm{I}_{\mathrm{K} \text {-ATP }}\right)$ or depression of inward calcium channel current $\left(\mathrm{I}_{\mathrm{Ca}}\right)$ can effect such a change (Figure $3 \mathrm{~A}$ and $\mathrm{B})$. This is more likely to manifest in the ECG as an ER pattern consisting of a $\mathrm{J}$ point elevation, slurring of the terminal part of the QRS and mild ST segment elevation. The ER pattern facilitates loss of the dome secondary to agents or conditions that produce a further outward shift of net current, leading to the development of ST segment elevation, phase 2 reentry and VT/VF (Figure 3C). Inhibition of $\mathrm{I}_{\text {to }}$ shifts net current in the inward direction, thus normalizing the ST segment and suppressing the $\mathrm{J}$ wave and arrhythmic manifestation.
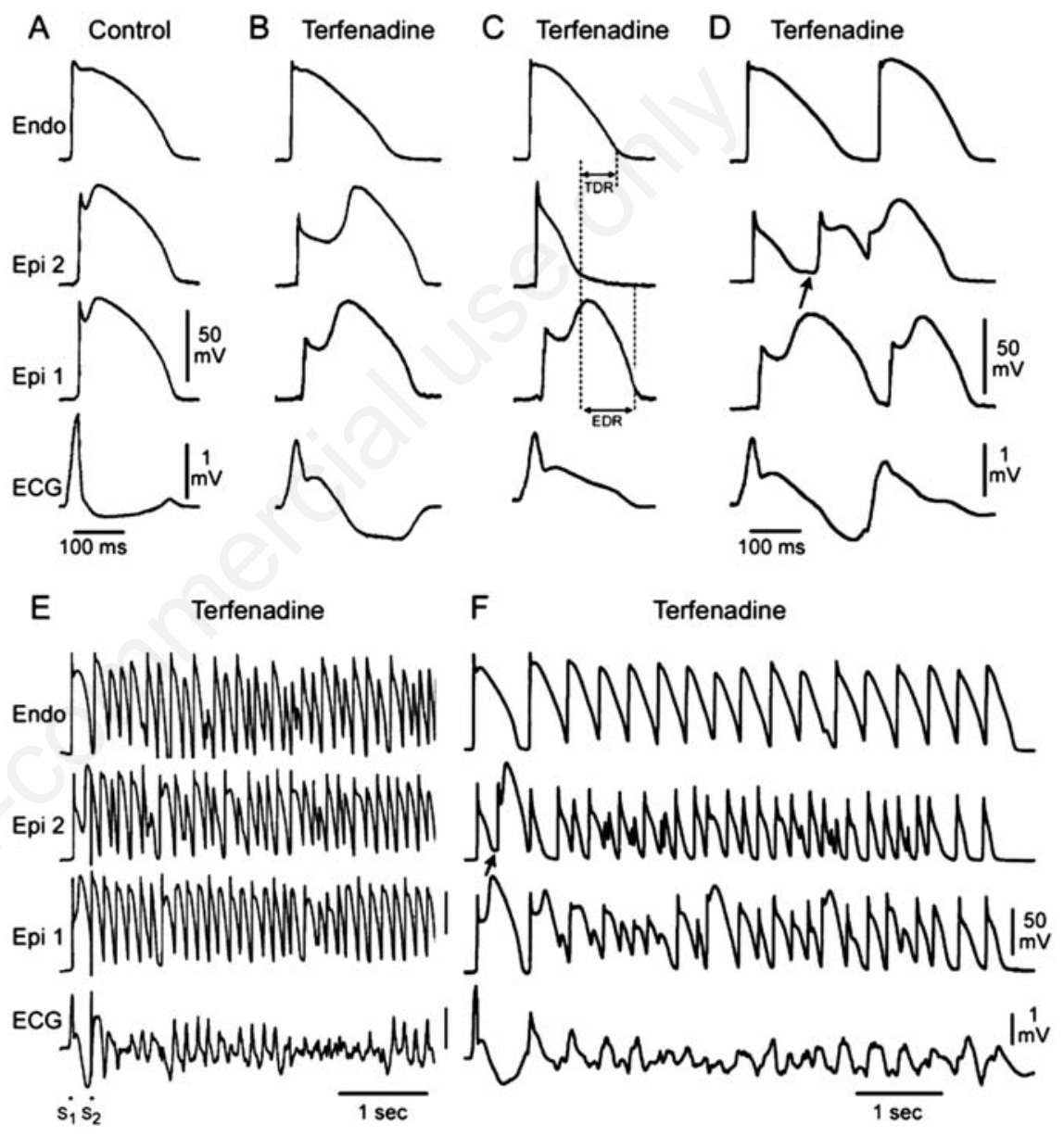

Figure 2. Cellular basis for electrocardiographic and arrhythmic manifestation of Brugada syndrome. Each panel shows transmembrane action potentials from one endocardial (top) and two epicardial sites together with a transmural electrocardiogram (ECG) recorded from a canine coronary-perfused right ventricular wedge preparation. A) Control [basic cycle length (BCL) $400 \mathrm{~ms}$. B) Combined sodium and calcium channel block with terfenadine $(5 \mu \mathrm{M})$ accentuates the epicardial action potential notch creating a transmural voltage gradient that manifests as an exaggerated J wave or ST segment elevation in the ECG. C) Continued exposure to terfenadine results in all-or-none repolarization at the end of phase 1 at some epicardial sites but not others, creating a local epicardial dispersion of repolarization (EDR) as well as a transmural dispersion of repolarization (TDR). D) Phase 2 reentry occurs when the epicardial action potential dome propagates from a site where it is maintained to regions where it has been lost giving rise to a closely coupled extrasystole. E) Extrastimulus (S1-S2=250 ms) applied to epicardium triggers a polymorphic ventricular tachycardia (VT). F) Phase 2 reentrant extrasystole triggers a brief episode of polymorphic VT (modified from Fish and Antzelevitch, $2004^{50}$ with permission). 


\section{Clinical manifestations}

\section{of J wave syndromes}

In both BrS and ERS, the manifestation of the $\mathrm{J}$ wave or ER is dynamic, ${ }^{27,59,60}$ with the most prominent ECG changes appearing just before the onset of VT/NF. ${ }^{20-27,43,59,60}$ Other ECG characteristics of ERS also closely match those of BrS, including the presence of accentuated $\mathrm{J}$ waves, ST segment elevation, pause and bradycardia-dependence, short coupled extrasystoleinduced polymorphic VT/VF. Suppression of the ECG features by isoproterenol or pacing in ER patients further supports the notion that they share common underlying electrophysiologic abnormalities with BrS patients. ${ }^{43}$ However, salient diagnostic features of BrS such as provocation by sodium channel blockers or positive signal averaged ECG are rarely observed in these ERS patients..$^{29,43}$ An exception to this rule appears to apply to ERS associated with SCN5A mutations. ${ }^{61}$ Kawata and coworkers recently showed that sodium channel blockers attenuate ER in patients with both ERS apparently due to slowing of transmural conduction so that $\mathrm{J}$ point shifts to a lower position on the terminal part of the QRS. ${ }^{62}$

Table 1 lists the various features common to BrS and ERS and possible underlying mechanisms. The table highlights the fact that the two syndromes display a strong male predominance and are similar with respect to the age at which the first event is documented. Both show great dynamicity as far as manifestations of the ECG phenotype and in both cases VT/VF is often precipitated by a very closely coupled premature beat. BrS and ERS respond similarly to Ito blockers such as quinidine, adrenergic agonists such as isoproterenol, and rapid heart rates or pacing rates; these intervention all produce an ameliorative effect. The ECG and arrhythmic manifestation of both BrS and ERS are exacerbated by increased vagal tone.

\section{Genetics of J wave syndromes}

$\mathrm{BrS}$ has been associated with mutations in twelve different genes (Table 2). Greater than 300 mutations in SCN5A $\left(\mathrm{Na}_{\mathrm{v}} 1.5, \mathrm{BrS1}\right)$ have been reported in $11-28 \%$ of $\mathrm{BrS}$ probands. ${ }^{63-65}$ Mutations in CACNA1C $\left(\mathrm{Ca}_{\mathrm{v}} 1.2, \mathrm{BrS} 3\right)$, CACNB2b ( $\left.\mathrm{Ca}_{\mathrm{v}} \beta 2 \mathrm{~b}, \mathrm{BrS} 4\right)$ and CACNA2D1 $\left(\mathrm{Ca}_{\mathrm{v}} \mathrm{a} 2, \mathrm{BrS} 9\right)$ are found in approximately $13 \%$ of probands. ${ }^{66,67}$ Mutations in glycerol-3phophate dehydrogenase 1-like enzyme gene (GPD1L, BrS2), SCN1B ( $\beta_{1}$-subunit of $\mathrm{Na}$ channel, BrS5), KCNE3 (MiRP2; BrS6), SCN3B ( $\beta 3$-subunit of $\mathrm{Na}$ channel, BrS7), KCNJ8 (BrS8), KCND3 (BrS10), MOG1 (BrS11) and SLMAP (BrS12) are more rare..$^{68-75}$ Mutations

\section{A Early Repolarization Syndrome in a Healthy Young Male}

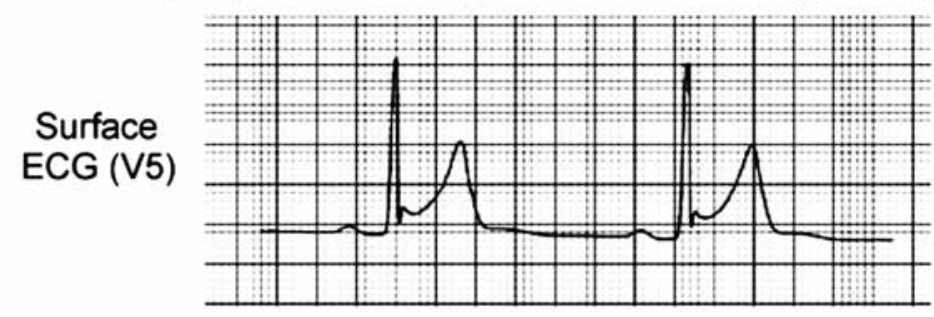

\section{B Canine Ventricular Action Potentials and ECG}
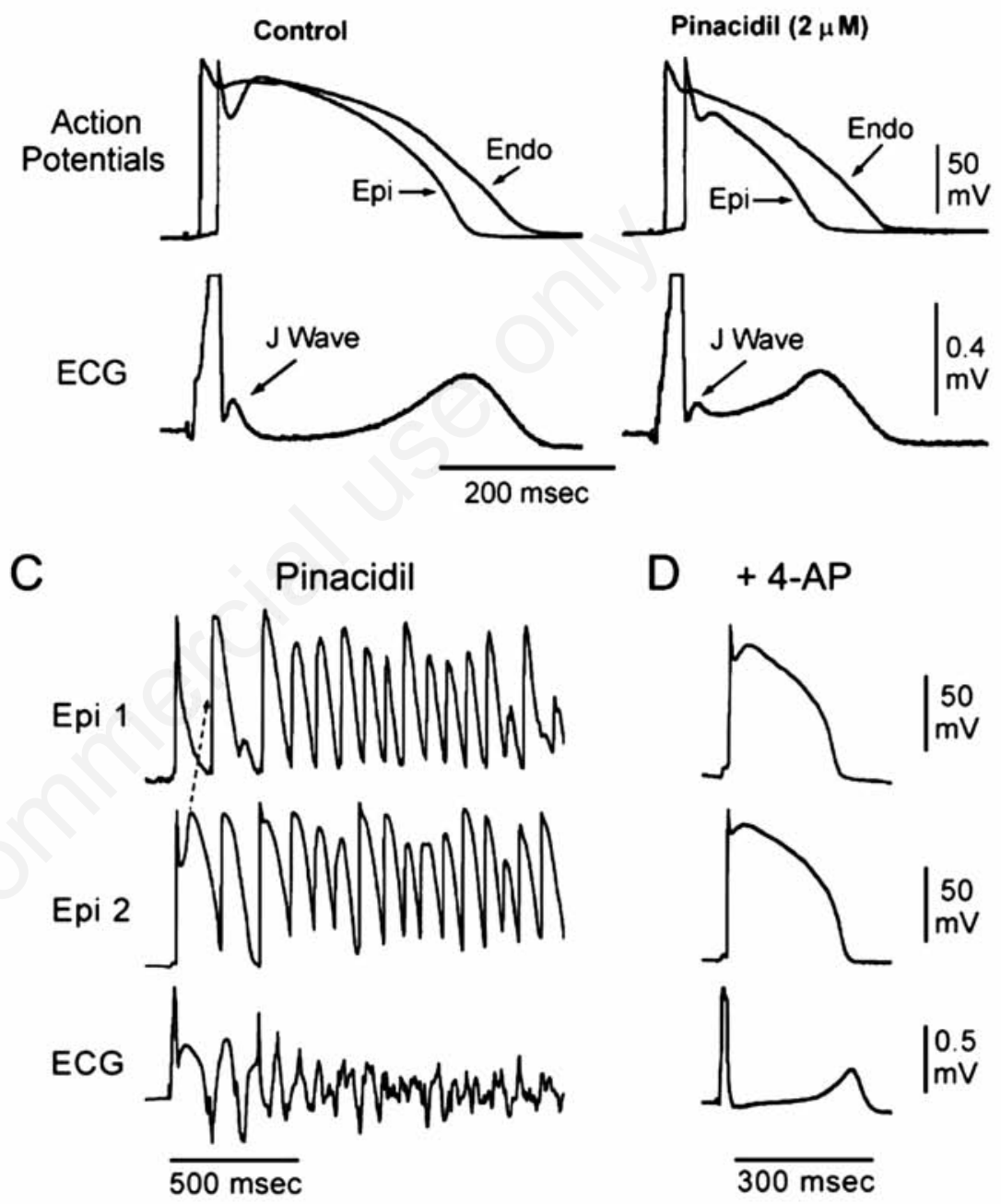

Figure 3. Cellular basis for the early repolarization syndrome. A) Surface electrocardiogram (ECG) (lead V5) recorded from a 17-year-old healthy African American male. Note the presence of a small J wave and marked ST segment elevation. B) Simultaneous recording of transmembrane action potentials from epicardial (Epi) and endocardial (Endo) regions and a transmural ECG in an isolated arterially perfused canine left ventricular wedge. A J wave in the transmural ECG is manifest due to the presence of an action potential notch in epicardium but not endocardium. Pinacidil ( $2 \mathrm{mM})$, an ATP-sensitive potassium channel opener, causes depression of the action potential dome in epicardium, resulting in ST segment elevation in the ECG resembling the early repolarization syndrome. Reprinted from Yan et al. ${ }^{48}$ with permission. C) $\mathrm{I}_{\mathrm{K}-\mathrm{ATP}}$ activation in the canine right ventricular wedge preparation using $2.5 \mathrm{uM}$ pinacidil produces heterogeneous loss of the AP dome in epicardium, resulting in ST segment elevation, phase 2 reentry and ventricular tachycardia and fibrillation (VT/VF) (Brugada syndrome phenotype). D) The I blocker, 4-aminopyridine (4-AP), restored the epicardial action potential (AP) dome, reduced both transmural and epicardial dispersion of repolarization, normalized the $S T$ segment and prevented phase 2 reentry and VT/VF in the continued presence of pinacidil (modified from Di Diego et al., 2004101, and Antzelevitch and Yan, $2010^{\circ}$ with permission). 
in these genes lead to loss of function in $\mathrm{I}_{\mathrm{Na}}$ and $\mathrm{I}_{\mathrm{Ca}}$, as well as to a gain of function in $\mathrm{I}_{\text {to }}$ or $\mathrm{I}_{\text {K-ATP* }}$

The genetic basis for ERS is gradually coming into better focus. The familial nature of ER pattern has been demonstrated in a number of studies. $^{33,76,77}$ The Framingham Heart Study reported that siblings of ER subjects are twice as likely to have ER than non-ER subjects [odds ratio (OR) 2.22, $\mathrm{P}<0.05$ ]. In another study of over 500 British families, ER was over two times more likely to occur in children (OR $2.54, \mathrm{P}=0.005)$ if one of the parents had an $E R$ ECG pattern. 33,76

ERS has been associated with mutations in 6 genes (Table 3 ). Consistent with the findings that $\mathrm{I}_{\mathrm{K} \text {-ATP }}$ activation can generate an ER pattern in canine ventricular wedge preparations, a rare variant in $K C N J 8$, responsible for the pore forming subunit of the $\mathrm{I}_{\mathrm{K} \text {-ATP }}$ channel, has recently been reported in a patients with ERS as well as BrS. ${ }^{71,78,79}$ Recent studies have identified loss of function mutations in the $\alpha$ and $\beta$ and $\alpha 2 \delta 1$ subunits of the cardiac L-type calcium channel (CACNA1C, CACNB2, and CACNA2D1) and as well as loss-of-function mutations in SCN5A in patients with ERS. ${ }^{61,67}$

Table 1. Features common to Brugada and early repolarization syndromes and possible underlying mechanisms.

\begin{tabular}{|c|c|c|c|c|}
\hline & BrS & ERS & \multicolumn{2}{|c|}{ Possible mechanism(s) } \\
\hline $\begin{array}{l}\text { Region associated } \\
\text { with highest arrhythmic risk }\end{array}$ & RVOT & Inferior myocardium & \multicolumn{2}{|c|}{ Increased levels of $\mathrm{I}_{\text {to }}$ and/or reduced inward currents } \\
\hline Male predominance & Yes $(75 \%)$ & Yes $(80 \%)$ & \multicolumn{2}{|c|}{$\begin{array}{l}\text { Testosterone modulation of ion currents underlying } \\
\text { the epicardial AP notch }\end{array}$} \\
\hline Average age of first event & $\sim 35-40$ & 42 & \multirow{2}{*}{\multicolumn{2}{|c|}{$\begin{array}{l}\text { Autonomic modulation of ion channel currents } \\
\text { underlying early phases of the epicardial AP }\end{array}$}} \\
\hline Dynamicity of ECG & High & High & & \\
\hline VTNF trigger & Short-coupled PVC & Short-coupled PVC & \multicolumn{2}{|c|}{ Phase 2 reentry } \\
\hline Ameliorative response to quinidine & Yes & Yes & \multicolumn{2}{|c|}{ Inhibition of $\mathrm{I}_{\mathrm{t}_{0}}$ and possible vagolytic effect } \\
\hline Ameliorative response to isoproterenol and cilostazol & Yes & Yes & \multicolumn{2}{|c|}{ Increased $\mathrm{I}_{\mathrm{Ca}}$ and faster heart rate } \\
\hline Ameliorative response to pacing & Yes & Yes & \multicolumn{2}{|c|}{$\begin{array}{l}\text { Reduced availability of } \mathrm{I}_{\text {to }} \text { due to slow recovery } \\
\text { from inactivation }\end{array}$} \\
\hline Vagally-mediated accentuation of ECG pattern & Yes & Yes & \multicolumn{2}{|c|}{$\begin{array}{l}\text { Direct effect to inhibit } \mathrm{I}_{\mathrm{Ca}} \text { and indirect effect } \\
\text { to increase } \mathrm{I}_{\text {to }} \text { (due to slowing of heart rate) }\end{array}$} \\
\hline \multicolumn{5}{|c|}{$\begin{array}{l}\text { BrS, Brugada syndrome; ERS, early repolarization syndrome; RVOT, right ventricular outflow tract; AP, action potential; ECG, elecrocardiogram; VTNF, ventricular tachycardia and fibrillation; PVC, premature ventricu- } \\
\text { lar contraction. }\end{array}$} \\
\hline \multicolumn{5}{|l|}{ Table 2. Genetic basis of Brugada syndrome. } \\
\hline Locus & Ion channel & & Gene/protein & $\%$ of proband \\
\hline $3 \mathrm{p} 21$ & $\mathrm{I}_{\mathrm{Na}}$ & & $S C N 5 A, N a_{v} 1.5$ & $11-28 \%$ \\
\hline $3 \mathrm{p} 24$ & $I_{\mathrm{Na}}$ & & GPDIL & Rare \\
\hline 12p13.3 & $\mathrm{I}_{\mathrm{Ca}}$ & & CACNAIC, $\mathrm{Ca}_{v} 1.2$ & $6.6 \%$ \\
\hline 10p12.33 & $\mathrm{I}_{\mathrm{Ca}}$ & & $C A C N B 2 b, C a_{v} \beta 2 b$ & $4.8 \%$ \\
\hline 19q13.1 & $\mathrm{I}_{\mathrm{Na}}$ & & $S C N 1 B, N a_{v} \beta 1$ & $1.1 \%$ \\
\hline $11 q 13-14$ & $\mathrm{I}_{\mathrm{to}}$ & & KCNE3, MiRP2 & Rare \\
\hline $11 q 23.3$ & $\mathrm{I}_{\mathrm{Na}}$ & & $S C N 3 B, N a_{v} \beta 3$ & Rare \\
\hline 12p11.23 & $\mathrm{I}_{\text {K-ATP }}$ & & KCNJ8, Kir6.1 & $2 \%$ \\
\hline $7 q 21.11$ & $\mathrm{I}_{\mathrm{Ca}}$ & & $A C N A 2 D 1, C a_{v} \alpha 2 d$ & $1.8 \%$ \\
\hline 1p13.2 & $\mathrm{I}_{\mathrm{to}}$ & & KCND3, $\mathrm{K}_{v} 4.3$ & Rare \\
\hline 17p13.1 & $\mathrm{I}_{\mathrm{Na}}$ & & MOG1 & Rare \\
\hline 3p21.2-p14.3 & $\mathrm{I}_{\mathrm{Na}}$ & & SLMAP & Rare \\
\hline
\end{tabular}

BrS, Brugada syndrome.

Table 3. Genetic basis of early repolarization syndrome.

\begin{tabular}{|c|c|c|c|c|}
\hline & Locus & Ion channel & Gene/protein & $\%$ of probands \\
\hline ERS1 & $12 p 11.23$ & $\mathrm{I}_{\text {K-ATP }}$ & KCNJ8, Kir6.1 & - \\
\hline ERS2 & 12p13.3 & $\mathrm{I}_{\mathrm{Ca}}$ & CACNAIC, $\mathrm{Ca}_{V} 1.2$ & $4.1 \%$ \\
\hline ERS3 & 10p12.33 & $\mathrm{I}_{\mathrm{Ca}}$ & $C A C N B 2 b, C a_{V} \beta_{2 b}$ & $8.3 \%$ \\
\hline ERS4 & $7 q 21.11$ & $\mathrm{I}_{\mathrm{Ca}}$ & CACNA2D1, Ca $a_{V} \alpha 2 d 1$ & $4.1 \%$ \\
\hline ERS5 & 12p12.1 & $\mathrm{I}_{\mathrm{K} \text {-ATP }}$ & ABCC9, SUR2A & - \\
\hline ERS6 & $3 p 21$ & $\downarrow \quad \mathrm{I}_{\mathrm{Na}}$ & SCN5A, NaV1.5 & - \\
\hline
\end{tabular}

ERS, early repolarization syndrome. 
Our working hypothesis is that an outward shift in repolarizing current secondary to a decrease in sodium or calcium channel currents or an increase in $\mathrm{I}_{\text {to }}, \mathrm{I}_{\mathrm{K} \text {-ATP }}, \mathrm{I}_{\mathrm{K}-\mathrm{ACh}}$, or other outward currents gives rise to the $\mathrm{J}$ wave syndromes (Figure 4). The particular phenotype depends on what part of the heart is principally affected and which ion channels are involved. We regard the $\mathrm{J}$ wave syndromes as a spectrum of disorders that involve accentuation of the epicardial action potential notch in different regions of heart, leading to the development of prominent $\mathrm{J}$ waves that predispose to the development of VT/NF. ${ }^{9}$

In the case of patients with BrS, the appearance of prominent $\mathrm{J}$ waves is limited to the leads facing the right ventricular outflow tract where $I_{\text {to }}$ is thought to be most intense. The more prominent $I_{\text {to }}$ in right ventricular epicardium provides for an outward shift in the balance of current, which promotes the appearance of the $J$ wave in this region of the ventricular myocardium. In the case of ERS, the appearance of prominent $\mathrm{J}$ waves may be limited to other regions of the ventricular myocardium because of the presence of heterogeneities in the distribution of other currents such as $\mathrm{I}_{\mathrm{K}-\mathrm{ATP}}$.

\section{Risk stratification}

As in most cases of BrS, bradycardia accentuates ST segment elevation, and tachycardia tends to normalize the ST segment in ERS. VF often occurs near midnight or in the early morning hours when heart rate is slower and parasympathetic tone is augmented. ${ }^{23,80}$

In BrS, the manifestation of spontaneous ST segment elevation has been associated with a higher risk for development of arrhythmic events. Risk stratification of asymptomatic patients remains a challenge. Indeed, the most debated issue has to do with risk stratification of asymptomatic BrS patients. Brugada et $a l{ }^{81,82}$ reported that the risk for developing VT/VF is much greater in patients who are inducible during electrophysiological study (EPS), whether or not a type 1 ST-segment elevation is spontaneously present and whether or not they are symptomatic. In asymptomatic spontaneous type 1 ECG patients, multivariate analysis showed that the only predictor of arrhythmic events is inducibility during EPS.

In sharp contrast, other studies ${ }^{83-89}$ failed to find an association between inducibility and cardiac arrhythmic events. The incidence of VT/NF events during follow-up was too low (annual event rate of $0.8-1 \%)^{83,84}$ to demonstrate value for risk stratification based on EPS inducibility. Of note, the last consensus conference published in $2005^{90}$ recommended that asymptomatic patients displaying a type 1 ST segment elevation (either spontaneously or after sodium channel blockade) undergo EPS if a family history of sudden cardiac death is suspected to be the result of BrS. EPS was also considered justified with a negative family history but a spontaneous type 1 ST segment elevation. If inducible for ventricular arrhythmia, implantation of an ICD was recommended either as a class IIa or IIb indication, meaning that conflicting evidence exists concerning usefulness and that the weight of evidence is either in favor of usefulness (class Ila) or usefulness is not well established (class IIb). The report also recommended that asymptomatic patients with no family history who develop a type 1 ST segment elevation only after sodium channel blockade should be closely followed up. The large number of studies conducted since the appearance of the last consensuses statement that have failed to demonstrate and association between inducibility and risk, call into question the value or need for EPS in asymptomatic Brugada patients. The reason for the large disparity between the results of the Brugada brothers and those from other centers is not clearly evident.

A recent study by Makimoto and coworkers reported that the number of extrastimuli that induced VT/NF serves as a prognostic indicator of risk in Brugada patients with type 1 ST segment elevation. They reported that single or double extrastimuli were adequate for programmed electrical stimulation in patients with BrS. ${ }^{91}$ Asymptomatic BrS patients with type I ST segment elevation are also at increased risk compared to those manifesting a saddleback or type II ST segment elevation. Some electrocardiographic patterns are associated with higher risk of symptoms or lifethreatening events in BrS, including higher Jpoint elevations, $\mathrm{QRS}$ durations $>100 \mathrm{~ms}$, and a prominent $r$ ' in lead aVR. ${ }^{92}$ Athletes do not appear to have a higher prevalence of Brugada ECG patterns, despite the fact that many athletes display an early repolarization patterns..$^{93}$

In the case of ERS, it is clear that the vast majority of individuals with ER are at no or minimal risk for arrhythmic events and sudden cardiac arrest. Our great challenge moving forward is to develop better risk stratification strategies and effective treatments for the $\mathrm{J}$ wave syndromes. Incidental discovery of a $\mathrm{J}$ wave on routine screening should not be interpreted as a marker of high risk for sudden cardiac death (SCD) since the odds for this leading to a fatal outcome is relatively low. ${ }^{39}$ However, mounting evidence suggests that careful attention should be paid to subjects with high risk ER. Who is at high risk?

Although we are still on a very steep learning curve, available data suggest a number of guidelines for risk stratification (Table 4). As with other inherited cardiac arrhythmia syndromes,

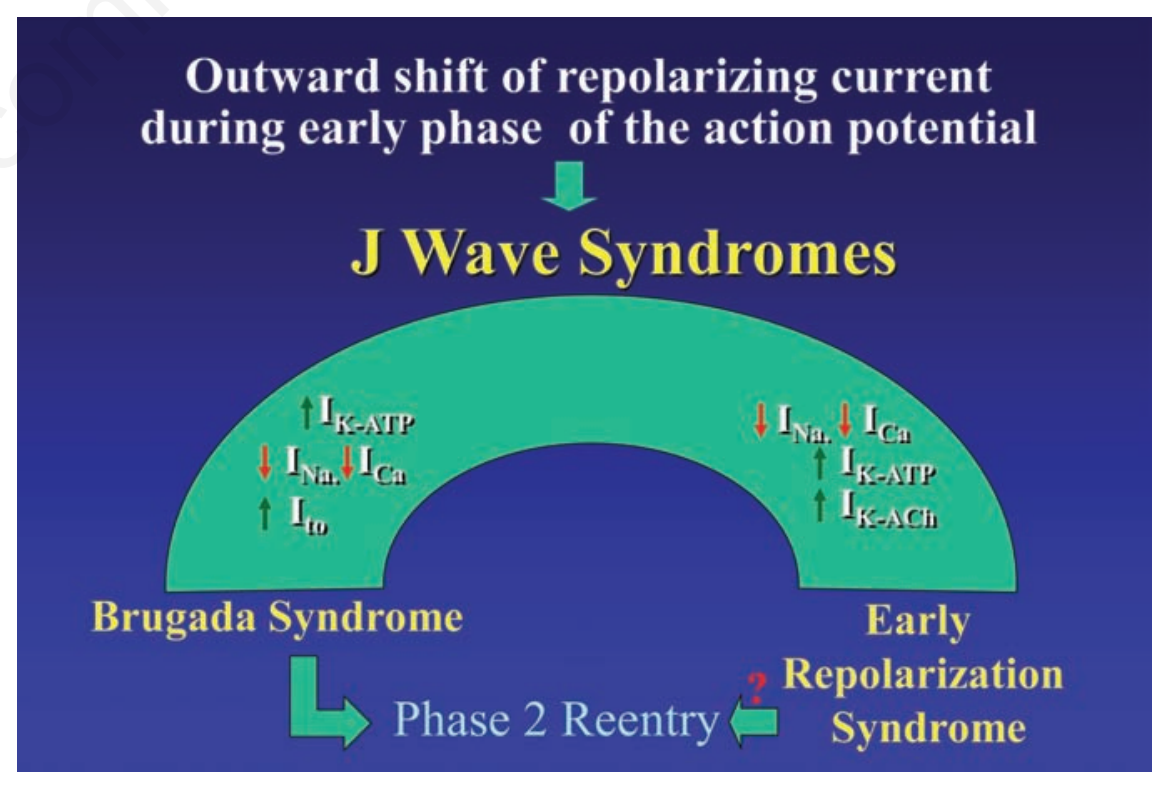

Figure 4. J wave syndromes. Schematic depicting our working hypothesis that an outward shift in repolarizing current due to a decrease in sodium or calcium channel currents or an increase in $I_{t}, I_{\mathrm{K}-\mathrm{ATP}}$ or $I_{\mathrm{K}-\mathrm{ACh}}$, or other outward currents can give rise to accentuated $\mathrm{J}$ waves associated with the Brugada syndrome and early repolarization syndrome (ERS). Both are thought to be triggered by closely-coupled phase 2 reentrant extrasystoles, but in the case of ERS a Purkinje source of ectopic activity is also suspected (modified from Antzelevitch and Yan, $2010^{\circ}$ with permission). 
Table 4. Risk stratification of patients with early repolarization pattern. Who is at risk?

\begin{tabular}{ll}
\hline 1 & Association of ER pattern with SCD, unexplained syncope, or unexplained family history of SCD \\
2 & J point or ST segment elevation of $0.2 \mathrm{mV}$ or greater in inferior and infero-lateral or global leads \\
\hline 3 & Transient J wave augmentation portends a high risk for VF in patients with ER \\
\hline 4 & Appearance of distinct and prominent J waves \\
\hline 5 & Association of ER pattern with abbreviated QT intervals \\
\hline 6 & Association with horizontal or descending ST segment \\
\hline 7 & Appearance of closely coupled extrasystoles \\
\hline ER, early repolarization; SCD, sudden cardiac death; VF, ventricular fibrillation.
\end{tabular}

association of ER with syncope, aborted SCD or family history of SCD is a marker of risk. Appearance of prominent and distinct J waves, ${ }^{94}$ transient augmentation of $\mathrm{J}$ waves or $\mathrm{J}$ point elevation of $>0.2 \mathrm{mV}$ in the inferior or inferolateral ECG leads should raise a red flag. ${ }^{31,33,95}$ Association of ER with horizontal or descending ST segment or short QT intervals. ${ }^{34,35,96}$ Finally, the appearance of very short-coupled extrasystoles are thought to be a marker of risk in that they likely reflect phase 2 reentry, the presumed trigger for the development of polymorphic VT in the $\mathrm{J}$ wave syndromes. ${ }^{9}$

Interestingly, recent studies have reported a higher prevalence of ER in victims of SCD than in survivors among subjects with acute coronary events, suggesting that the presence of ER increases the vulnerability to fatal arrhythmia during acute myocardial ischemia. ${ }^{97-99}$ The ion channel current most important in development of arrhythmogenesis associated with ischemia is $\mathrm{I}_{\mathrm{K} \text {-ATP. }}$ These findings are consistent with the discovery that gain-of-function mutations in the genes that encode the $\mathrm{I}_{\mathrm{K} \text {-ATP }}$ underlie many cases of $\mathrm{I}_{\mathrm{K} \text {-ATP }}{ }^{71,78,79,100}$ These results provide a possible mechanistic link to increased arrhythmic risk in patients displaying an ER pattern on their ECG.

\section{References}

1. Junttila MJ, Sager SJ, Tikkanen JT, et al. Clinical significance of variants of $\mathrm{J}$ points and J-waves: early repolarization patterns and risk. Eur Heart J 2012;33: 2639-43.

2. Gussak I, Bjerregaard P, Egan TM, Chaitman BR. ECG phenomenon called the $\mathrm{J}$ wave. History, pathophysiology, and clinical significance. J Electrocardiol 1995;28:49-58.

3. Osborn JJ. Experimental hypothermia: respiratory and blood $\mathrm{pH}$ changes in relation to cardiac function. Am J Physiol 1953;175:389-98.

4. Clements SD, Hurst JW. Diagnostic value of ECG abnormalities observed in subjects accidentally exposed to cold. Am J Cardiol 1972;29:729-34.

5. Thompson R, Rich J, Chmelik F, Nelson WL. Evolutionary changes in the electrocardiogram of severe progressive hypothermia. J Electrocardiol 1977;10:67-70.

6. Eagle K. Images in clinical medicine. Osborn waves of hypothermia. N Engl J Med 1994;10:680.

7. Kraus F. Ueber die wirkung des kalziums auf den kreislauf. Dtsch Med Wochenschr. 1920;46:201-3.

8. Sridharan MR, Horan LG. Electrocardiographic $\mathrm{J}$ wave of hypercalcemia. Am J Cardiol 1984;54:672-3.

9. Antzelevitch C, Yan GX. J wave syndromes. Heart Rhythm 2010;7:549-58.

10. Phillipson EA, Herbert FA. Accidental exposure to freezing: clinical and laboratory observations during convalescence from near-fatal hypothermia. Can Med Assoc J 1967;97:786-92.

11. Okada M, Nishimura F, Yoshino $\mathrm{H}$, et al. The $\mathrm{J}$ wave in accidental hypothermia. $\mathrm{J}$ Electrocardiol 1983;16:23-8.

12. Hugo N, Dormehl IC, Van Gelder AL. A positive wave at the J-point of electrocardiograms of anaesthetized baboons. J

13. West TC, Frederickson EL, Amory DW. Single fiber recording of the ventricular response to induced hypothermia in the anesthetized dog. Correlation with multicellular parameters. Circ Res 1959;7:8808.

14. Santos EM, Frederick KC. Electrocardiographic changes in the dog during hypothermia. Am Heart J 1957;55:415-20.

15. Wasserburger RH, Alt WJ. The normal RST segment elevation variant. Am J Cardiol 1961;8:184-92.

16. Mehta MC, Jain AC. Early repolarization on scalar electrocardiogram. Am J Med Sci 1995;309:305-11.

17. Gussak I, Antzelevitch C. Early repolarization syndrome: clinical characteristics and possible cellular and ionic mechaMed Primatol 1988;17:347-52. nisms. J Electrocardiol 2000;33:299-309.

18. Yan GX, Antzelevitch C. Cellular basis for the Brugada syndrome and other mechanisms of arrhythmogenesis associated with ST segment elevation. Circulation 1999;100:1660-6.

19. Bjerregaard P, Gussak I, Kotar Sl, Gessler JE. Recurrent synocope in a patient with prominent J-wave. Am Heart J 1994;127: 1426-30.

20. Yan GX, Antzelevitch C. Cellular basis for the electrocardiographic J wave. Circulation 1996;93:372-9.

21. Geller JC, Reek S, Goette A, Klein HU. Spontaneous episode of polymorphic ventricular tachycardia in a patient with intermittent Brugada syndrome. J Cardiovasc Electrophysiol 2001;12:1094.

22. Daimon M, Inagaki M, Morooka S, et al. Brugada syndrome characterized by the appearance of J waves. PACE 2000;23:4056.

23. Kalla H, Yan GX, Marinchak R. Ventricular fibrillation in a patient with prominent $\mathrm{J}$ (Osborn) waves and ST segment elevation in the inferior electrocardiographic leads: a Brugada syndrome variant? J Cardiovasc Electrophysiol 2000;11:95-8.

24. Komiya N, Imanishi R, Kawano H, et al. Ventricular fibrillation in a patient with prominent $\mathrm{J}$ wave in the inferior and lateral electrocardiographic leads after gastrostomy. PACE 2006;29:1022-4.

25. Shinohara T, Takahashi N, Saikawa T, Yoshimatsu H. Characterization of J wave in a patient with idiopathic ventricular fibrillation. Heart Rhythm 2006;3:1082-4.

26. Riera AR, Ferreira C, Schapachnik E, et al. Brugada syndrome with atypical ECG: downsloping ST-segment elevation in inferior leads. J Electrocardiol 2004;37: 101-4.

27. Shu J, Zhu T, Yang L, et al. ST-segment elevation in the early repolarization syndrome, idiopathic ventricular fibrillation, and the Brugada syndrome: cellular and clinical linkage. J Electrocardiol 2005;38:26-32.

28. Haissaguerre M, Derval N, Sacher F, et al. Sudden cardiac arrest associated with early repolarization. $\mathrm{N}$ Engl $\mathrm{J}$ Med 2008;358:2016-23.

29. Nam GB, Kim YH, Antzelevitch C. Augmentation of $\mathrm{J}$ waves and electrical storms in patients with early repolarization. N Engl J Med 2008;358:2078-9.

30. Rosso R, Kogan E, Belhassen B, et al. Jpoint elevation in survivors of primary ventricular fibrillation and matched control subjects: incidence and clinical significance. J Am Coll Cardiol 2008;52: 1231-8.

31. Tikkanen JT, Anttonen 0, Junttila MJ, et al. Long-term outcome associated with 
early repolarization on electrocardiography. N Engl J Med 2009;361:2529-37.

32. Sinner MF, Reinhard W, Muller M, et al. Association of early repolarization pattern on ecg with risk of cardiac and all-cause mortality: a population-based prospective cohort study (MONICA/KORA). PLoS Med 2010;7:e1000314.

33. Noseworthy PA, Tikkanen JT, Porthan K, et al. The early repolarization pattern in the general population clinical correlates and heritability. J Am Coll Cardiol 2011; 57:2284-9.

34. Tikkanen JT, Junttila MJ, Anttonen 0, et al. Early repolarization: electrocardiographic phenotypes associated with favorable long-term outcome. Circulation 2011;123:2666-73.

35. Burashnikov A, Antzelevitch C. Evaluation of: [Tikkanen JT, et al. Early repolarization: electrocardiographic phenotypes associated with favorable long-term outcome. Circulation 2011 Jun 14; 123(23):2666-73; doi: 10.1161/CIRCULATIONAHA.110.014068]. Faculty of 1000; 6 July 2011. Available from: F1000.com/ 11746956

36. Gross GJ. Early repolarization and ventricular fibrillation: vagally familiar? Heart Rhythm 2010;7:653-4.

37. Bastiaenen R, Hedley PL, Christiansen M, Behr ER. Therapeutic hypothermia and ventricular fibrillation storm in early repolarization syndrome. Heart Rhythm 2010;7:832-4.

38. Mizumaki K, Nishida K, Iwamoto J, et al. Early repolarization in Wolff-ParkinsonWhite syndrome: prevalence and clinical significance. Europace 2011;13:1195-200.

39. Rosso R, Adler A, Halkin A, Viskin S. Risk of sudden death among young individuals with $\mathrm{J}$ waves and early repolarization: putting the evidence into perspective. Heart Rhythm 2011;8:923-9.

40. Haruta D, Matsuo $\mathrm{K}$, Tsuneto A, et al. Incidence and prognostic value of early repolarization pattern in the 12 -lead electrocardiogram. Circulation 2011;123: 2931-7.

41. Patel RB, Ng J, Reddy V, et al. Early repolarization associated with ventricular arrhythmias in patients with chronic coronary artery disease. Circ Arrhythm Electrophysiol 2010;3:489-95.

42. Shimizu W, Matsuo K, Kokubo Y, et al. Sex hormone and gender difference-role of testosterone on male predominance in Brugada syndrome. J Cardiovasc Electrophysiol 2007;18:415-21.

43. Nam GB, Ko KH, Kim J, et al. Mode of onset of ventricular fibrillation in patients with early repolarization pattern vs. Brugada syndrome. Eur Heart J 2010; 31:330-9.
44. Litovsky SH, Antzelevitch C. Transient outward current prominent in canine ventricular epicardium but not endocardium. Circ Res 1988;62:116-26.

45. Antzelevitch C, Sicouri S, Litovsky SH, et al. Heterogeneity within the ventricular wall. Electrophysiology and pharmacology of epicardial, endocardial, and M cells. Circ Res 1991;69:1427-49.

46. Antzelevitch C, Yan GX. J-wave syndromes. from cell to bedside. J Electrocardiol 2011;44:656-61.

47. Antzelevitch C, Yan GX. Cellular and ionic mechanisms responsible for the Brugada syndrome. J Electrocardiol 2000;33:33-9.

48. Yan GX, Lankipalli RS, Burke JF, et al. Ventricular repolarization components on the electrocardiogram: cellular basis and clinical significance. J Am Coll Cardiol 2003;42:401-9.

49. Calloe K, Cordeiro JM, Di Diego JM, et al. A transient outward potassium current activator recapitulates the electrocardiographic manifestations of Brugada syndrome. Cardiovasc Res 2009;81:686-94.

50. Fish JM, Antzelevitch C. Role of sodium and calcium channel block in unmasking the Brugada syndrome. Heart Rhythm 2004;1:210-7.

51. Shimizu W, Antzelevitch C, Suyama K, et al. Effect of sodium channel blockers on ST segment, QRS duration, and corrected QT interval in patients with Brugada syndrome. J Cardiovasc Electrophysiol 2000;11:1320-9.

52. Brugada R, Brugada J, Antzelevitch C, et al. Sodium channel blockers identify risk for sudden death in patients with ST-segment elevation and right bundle branch block but structurally normal hearts. Circulation 2000;101:510-5.

53. Morita H, Morita ST, Nagase S, et al. Ventricular arrhythmia induced by sodium channel blocker in patients with Brugada syndrome. J Am Coll Cardiol 2003;42:1624-31.

54. Gussak I, Antzelevitch C, Bjerregaard P, et al. The Brugada syndrome: clinical, electrophysiologic and genetic aspects. J Am Coll Cardiol 1999;33:5-15.

55. Krishnan SC, Antzelevitch C. Flecainideinduced arrhythmia in canine ventricular epicardium. Phase 2 reentry? Circulation 1993;87:562-72.

56. Postema PG, van Dessel PFHM, Kors JA, et al. Local depolarization abnormalities are the dominant pathophysiologic mechanism for type 1 electrocardiogram in Brugada syndrome: a study of electrocardiograms, vectorcardiograms, and body surface potential maps during ajmaline provocation. $\mathrm{J}$ Am Coll Cardiol 2010;55: 789-97.

57. Nademanee K, Veerakul G, Chandanamattha $\mathrm{P}$, et al. Prevention of ventricular fibrillation episodes in Brugada syndrome by catheter ablation over the anterior right ventricular outflow tract epicardium. Circulation 2011;123: 1270-9.

58. Wilde AA, Postema PG, Di Diego JM, et al. The pathophysiological mechanism underlying Brugada syndrome: depolarization versus repolarization. J Mol Cell Cardiol 2010;49:543-53.

59. Kasanuki H, Ohnishi S, Ohtuka M, et al. Idiopathic ventricular fibrillation induced with vagal activity in patients without obvious heart disease. Circulation 1997; 95:2277-85.

60. Matsuo K, Shimizu W, Kurita T, et al. Dynamic changes of 12-lead electrocardiograms in a patient with Brugada syndrome. J Cardiovasc Electrophysiol 1998; 9:508-12.

61. Watanabe H, Nogami A, Ohkubo K, et al. Electrocardiographic characteristics and SCN5A mutations in idiopathic ventricular fibrillation associated with early repolarization. Circ Arrhythm Electrophysiol 2011;4:874-81.

62. Kawata H, Noda T, Yamada Y, et al. Effect of sodium-channel blockade on early repolarization in inferior/lateral leads in patients with idiopathic ventricular fibrillation and Brugada syndrome. Heart Rhythm 2012;9:77-83.

63. Chen Q, Kirsch GE, Zhang D, et al. Genetic basis and molecular mechanisms for idiopathic ventricular fibrillation. Nature 1998;392:293-6.

64. Schulze-Bahr E, Eckardt L, Breithardt G, et al. Sodium channel gene (SCN5A) mutations in 44 index patients with Brugada syndrome: different incidences in familial and sporadic disease. Hum Mutat 2003;21:651-2.

65. Kapplinger JD, Wilde AAM, Antzelevitch $\mathrm{C}$, et al. A worldwide compendium of putative Brugada syndrome associated mutations in the SCN5A encoded cardiac sodium channel. Heart Rhythm 2009;6:S392 Abstract.

66. Antzelevitch C, Pollevick GD, Cordeiro $\mathrm{JM}$, et al. Loss-of-function mutations in the cardiac calcium channel underlie a new clinical entity characterized by STsegment elevation, short QT intervals, and sudden cardiac death. Circulation 2007;115:442-9.

67. Burashnikov E, Pfeiffer R, BarajasMartinez H, et al. Mutations in the cardiac L-type calcium channel associated $\mathrm{J}$ wave sydnrome and sudden cardiac death. Heart Rhythm 2010;7:1872-82.

68. London B, Michalec M, Mehdi H, et al. Mutation in glycerol-3-phosphate dehydrogenase 1 like gene (GPD1-L) decreases cardiac $\mathrm{Na}^{+}$current and causes inherited arrhythmias. Circulation 2007;116: 
2260-8.

69. Watanabe H, Koopmann TT, Le Scouarnec $\mathrm{S}$, et al. Sodium channel b1 subunit mutations associated with Brugada syndrome and cardiac conduction disease in humans. J Clin Invest 2008;118:2260-8.

70. Delpón E, Cordeiro JM, Núñez L, et al. Functional effects of KCNE3 mutation and its role in the development of Brugada syndrome. Circ Arrhythm Electrophysiol 2008;1:209-18.

71. Medeiros-Domingo A, Tan BH, Crotti L, et al. Gain-of-function mutation S422L in the KCNJ8-encoded cardiac K(ATP) channel Kir6.1 as a pathogenic substrate for Jwave syndromes. Heart Rhythm 2010;7: 1466-71.

72. Giudicessi JR, Ye D, Tester DJ, et al. Transient outward current (Ito) gain-offunction mutations in the KCND3-encoded Kv4.3 potassium channel and Brugada syndrome. Heart Rhythm 2011;8:1024-32.

73. Cranefield PF, Hoffman BF. Conduction of the cardiac impulse. II. Summation and inhibition. Circ Res 1971;28:220-33.

74. Kattygnarath D, Maugenre S, Neyroud N, et al. MOG1: a new susceptibility gene for Brugada syndrome. Circ Cardiovasc Genet 2011;4:261-8.

75. Ishikawa T, Sato A, Marcou CA, et al. A novel disease gene for Brugada syndrome: sarcolemmal membrane-associated protein gene mutations impair intracellular trafficking of hNav1.5. Circ Arrhythm Electrophysiol 2012;5:1098-107.

76. Reinhard W, Kaess BM, Debiec R, et al. Heritability of early repolarization: a population-based study. Circ Cardiovasc Genet 2011;4:134-8.

77. Nunn LM, Bhar-Amato J, Lowe MD, et al. Prevalence of J-point elevation in sudden arrhythmic death syndrome families. J Am Coll Cardiol 2011;58:286-90.

78. Haissaguerre M, Chatel S, Sacher F, et al. Ventricular fibrillation with prominent early repolarization associated with a rare variant of $\mathrm{KCNJ} 8 / \mathrm{K}_{\mathrm{ATP}}$ channel. J Cardiovasc Electrophysiol 2009;20:93-8.

79. Barajas-Martinez H, Hu D, Ferrer T, et al. Molecular genetic and functional association of Bugada and early repolarization syndromes with S422L missense mutation in KCNJ8. Heart Rhythm 2012;9:548-55.

80. Qi X, Sun F, An X, Yang J. A case of
Brugada syndrome with ST segment elevation through entire precordial leads. Chin J Cardiol 2004;32:272-3.

81. Brugada J, Brugada R, Brugada P. Right bundle-branch block and ST-segment elevation in leads $V_{1}$ through $V_{3}$. A marker for sudden death in patients without demonstrable structural heart disease. Circulation 1998;97:457-60.

82. Brugada P, Brugada R, Brugada J. Patients with an asymptomatic Brugada electrocardiogram should undergo pharmacological and electrophysical testing. Circulation 2005;112:279-85.

83. Priori SG, Napolitano C. Management of patients with Brugada syndrome should not be based on programmed electrical stimulation. Circulation 2005;112:285-91.

84. Eckardt L, Probst V, Smits JP, et al. Longterm prognosis of individuals with right precordial ST-segment-elevation Brugada syndrome. Circulation 2005;111:257-63.

85. Gehi AK, Duong TD, Metz LD, et al. Risk stratification of individuals with the brugada electrocardiogram: a meta-analysis. J Cardiovasc Electrophysiol 2006;17:57783.

86. Ohkubo K, Watanabe I, Takagi Y, et al. Electrocardiographic and electrophysiologic characteristics in patients with brugada type electrocardiogram and inducible ventricular fibrillation. Circ J 2007;71:1437-41.

87. Paul M, Gerss J, Schulze-Bahr E, et al. Role of programmed ventricular stimulation in patients with Brugada syndrome: a meta-analysis of worldwide published data. Eur Heart J 2007;28:2126-33.

88. Rosso R, Glick A, Glikson M, et al. Outcome after implantation of cardioverter defribrillator in patients with Brugada syndrome: a multicenter Israeli study (ISRABRU). Isr Med Assoc J 2008;10:435-9.

89. Probst V, Veltmann C, Eckardt L, et al. Long-term prognosis of patients diagnosed with Brugada syndrome: results from the FINGER Brugada Syndrome Registry. Circulation 2010;121:635-43.

90. Antzelevitch C, Brugada P, Borggrefe M, et al. Brugada syndrome: report of the second consensus conference: endorsed by the Heart Rhythm Society and the European Heart Rhythm Association. Circulation 2005;111:659-70.
91. Makimoto H, Kamakura S, Aihara N, et al. Clinical impact of the number of extrastimuli in programmed electrical stimulation in patients with Brugada type 1 electrocardiogram. Heart Rhythm 2012;9:242-8.

92. Junttila MJ, Brugada P, Hong K, et al. Differences in 12-lead electrocardiogram between symptomatic and asymptomatic Brugada syndrome patients. J Cardiovasc Electrophysiol 2008;19:380-3.

93. Klatsky AL, Oehm R, Cooper RA, et al. The early repolarization normal variant electrocardiogram: correlates and consequences. Am J Med 2003;115:171-7.

94. Merchant FM, Noseworthy PA, Weiner RB, et al. Ability of terminal QRS notching to distinguish benign from malignant electrocardiographic forms of early repolarization. Am J Cardiol 2009;104:1402-6.

95. Boineau JP. The early repolarization variant-normal or a marker of heart disease in certain subjects. J Electrocardiol 2007;40:3.e1-3.e10.

96. Watanabe H, Makiyama T, Koyama T, et al. High prevalence of early repolarization in short QT syndrome. Heart Rhythm 2010;7:647-52.

97. Tikkanen JT, Wichmann V, Junttila MJ, et al. Association of early repolarization and sudden cardiac death during an acute coronary event. Circ Arrhythm Electrophysiol 2012;5:714-8.

98. Naruse Y, Tada H, Harimura Y, et al. Early repolarization is an independent predictor of occurrences of ventricular fibrillation in the very early phase of acute myocardial infarctions. Circ Arrhythm Electrophysiol 2012;5:506-13.

99. Patel RB, Ilkhanoff L, Ng J, et al. Clinical characteristics and prevalence of early repolarization associated with ventricular arrhythmias following acute ST-elevation myocardial infarction. Am J Cardiol 2012; 110:615-20.

100. Antzelevitch C. Genetic, molecular and cellular mechanisms underlying the $\mathrm{J}$ wave syndromes. Circ J 2012;76:1054-65.

101. Di Diego JM, Cordeiro JM, Goodrow RJ, et al. Ionic and cellular basis for the predominance of the Brugada syndrome phenotype in males. Circulation 2002;106:2004-11. 